\title{
PERENCANAAN KONSTRUKSI BETON SLIPWAY - 150 LWT
}

\author{
Budhi Dharma \\ Program Studi Diploma III Teknik Sipil \\ Fakultas Teknik Universitas Diponegoro
}

\begin{abstract}
Budhi Dharma, in paper Construction Planning of Slipway - 150 LWT Concrete explain that in shipyard planning major facility types shipyard slipway suitable transverse system was built in the open or closed.To ship with 150 tons LWT according to the register BKI got main dimension vessels = 34 meters LOA,30 meters LP, 6 meters $B$, the ship draft $T=2,2$ meters, and empty vessel draft Tk =1,18 meters and block coefficient $=0,68$.

Of the main dimension of the vessel were then long slipway, heavy lorries and heavy lorries transfer launchers after the total weight is obtained the dimensions of the placement of concrete beam rail and lorry.
\end{abstract}

Keyword : Slip way and structure concrete

\section{PENDAHULUAN}

Didalam perencanaan galangan kapal, baik untuk galangan terbuka maupun daerah tertutup faktor utama yang harus diperhatikan adalah keadaan dari lokasi yang memungkinkan untuk dibangun, keadaan ini meliputi :

- Luas areal daratan dan perairan

- Elevasi tanah daratan dan tanah dasar perairan

- Data dari pasang surut air masimum dan minimum

Hal ini sangat penting untuk mendukung kemajuan galangan kapal, karena dengan bertambahnya sarana galangan tanpa diimbangi oleh keadaan setempat dapat menjadi hambatan untuk mencapai kemajuan selanjutnya.

Landasan tarik (slip way) adalah merupakan failitas utama dari galangan kapal, berupa landasan miring yangdibuat dari konstruksi beton bertulang, sebagian konstruksinya tercelup dibawah air dan lainnya terletak diatas air.

Pada landasan tersebut dipasang rel yang cukup kuat dan mampu menahan beban dari berat lori dan berat kapal yang akan dinaikkan untuk diperbaiki. Diatas lori diletakkan keel block dan side block untuk dudukan kapal.

Dari darat sampai dalamnya perairan mempunyai sudut kemiringan yangsudah tertentu sesuai dengan tipe dan besar kecilnya slipway yang direncanakan. Menurut jenisnya slipway ada 2 macam:

- $\quad$ Slipway sistem memanjang (End launching)

- $\quad$ Slipway sistem melintang (Side launching)

Keduanya biasa dipakai untuk pekerjaan kapal berukuran kecil, bila kondisi slipway masih memungkinkan dapat dipakai untuk pekerjaan kapalkapal yang berukuran sedang.
Prinsip kerja dari landasan tarik baik sistem melintang maupun sistem membujur mempunyai rencana kerja yang sama, juga peralatan yang dipakai tidak berbeda. Tetapi perbedaan nya hanya pada posisi kapalnya. Bila pada landasan tarik membujur posisi kapal yang duduk di landasan atau lori miring kearah memanjang sejajar dengan kemiringan landasan. Sedangkan pada landasan tarik sistem melintang posisi kapal mendatar sejajar dengan permukaan air sehingga lori nya dibuat sesuai dengan posisi kapal yang mendatar.

Galangan kapal dengan type slipway ini cocok bila dibangun disepanjang pantura pulau jawa misalnya di Cirebon, Tegal, Pekalongan, Batang, Kendal, Demak, Pati, Rembang sampai dengan pantai utara Jawa Timur, karena daerah tersebut banyak terdapat dermaga bongkar muat kapal muatan kayu, kapal penangkap ikan dan kapal lainnya yang mempunyai berat rata-rata kurang dari 150 LWT. Untuk selanjutnya penulis hanya membahas permasalahan penentuan ukuran kapal.

\section{PERENCANAAN GALANGAN KAPAL}

Pada perencanaan galangan kapal, untuk mendapatkan hasil perencanaan yang baik serta dapat mendukung pengoperasiannya maka harus dibuat susunan daripada letak atau lay out galangan yang menggambarkan cara kerja dari fasilitas utama dan fasilitas penunjangnya secara komprehensip dan harus dipikirkan kemungkinannya terhadap pengembangan perusahaan.

\section{Penentuan Ukuran Utama Kapal Kapasitas Angkat Slip Way 150 Ton}

Dari Ukuran Utama kapal yang akan diketahui berapa berat yang akan dibuat atau dinaikkan slipway. Untuk menentukan kapasitas angkat yang sesuai, maka diambil Ukuran Utama dari Kapal Pembanding dalam buku Register BKI yaitu sebagai berikut : 
$\mathrm{LOA}=34,00$ meter

$\mathrm{LPP}=30,00$ meter

Lebar kapal B = 6,00 meter

Sarat kapal $\mathrm{T}=2,20$ meter

Sarat kapal kosong $\mathrm{Tk}=1,18$ meter

Koefisien blok $=0,68$

$\mathrm{D}=30,00 \times 6,00 \times 2,20 \times 0,68 \times 1,025 \times 1,003=$ 276,84 TON

$\mathrm{DWT}=0,46 \times 272,20=127,35 \mathrm{TON}$

$\mathrm{LWT}=272,20-125,20=149,90 \mathrm{TON}$

LWT adalah berat baja kapal, mesin dan perlengkapannya pada kapal baru yang selesai dibangun $=149,49 \rightarrow 150$ TON.

Untuk menurunkannya dipergunakan lory peluncur yang merupakan satu kesatuan dengan lori transfer sehingga posisi kapal yang dibangun duduk di atas nya secara mendatar sejajar dengan permukaan perairan yang semuanya digerakkan dengan motor listrik untuk memutar winch.

Untuk menaik turunkan dipergunakan lory peluncur yang merupakan satu kesatuan dengan lori transfer yang semuanya digerakkan dengan motor listrik untuk memutar winch.

Galangan kapal tipe slipway ini sangat cocok bila dibangun disepanjang pantura pulau jawa misalnya Cirebon, Tegal, Pekalongan, Batang, Kendal, Demak, Juwana, Rembang dan lain lain, karena daerah tersebut tempat bermukimnya nelayannelayan kapal penangkap ikan dan kapal-kapal lainnya yang mempunyai berat rata-rata kurang dari 150 LWT.

\section{Perencanaan Slip Way Melintang}

Tipe slipway dan perlengkapaanya sangat dipengaruhi oleh beberapa faktor antara lain : tipe dan ukuran utama kapal, sifat konstruksi dari kapal yang akan dibangun atau direparasi yang menyesuaikan kondisi setempat. Kondisi setempat meliputi panjang daerah yang dapat digunakan untuk peluncuran, tipe dari peluncuran, pasang surut air laut dan kondisi suhu udara setempat dan lain-lain.

Landasan pembangunan slipway penggunaannya sangat dipengaruhi oleh kondisikondisi setempat yaitu situasi dan luas areal dimana landasan slipway itu dibangun.

Landasan tarik slipway melintang didalam pelaksanaan peluncuran kapal diluncurkan melintang dengan posisi kapal dalam keadaan datar (rata), keuntungannya adalah selain untuk membangun kapalbaru dapat juga dipakai untuk perbaikan kapal atau reparasi dan pelaksanaan pekerjaan pembangunan dan perbaikan dapat lebih cepat karena kapal dalam keadaan mendatar.
Didalam pembuatan landasan (slipway) yang harus diperhatikan adalah sebagai berikut :

- Landasan slipway harus mampu menahan berat lori dan kapalnya

- Landasan slipway harus cukup luas

- Landasan slipway harus dilengkapi dengan pemberian tenaga listrik (power) untuk suplai arus listrik, dan dilengkapi saluran air untuk mengatasi bila sewaktu-waktu terjadi kebakaran dan lain-lain.

Untuk dapat merencanakan slipway, harus diketahui beberapa data yang menjadi dasar dalam perhitungan slipway yaitu sebagai berikut :

- Luas areal yang direncanakan harus diperhatikan untuk pengembangan galangan di masa depan.

- Kondisi pasang surut yang terdapat pada perairan rencana galangan, perbedaan pasang surut tiap bulaan $=210 \mathrm{~cm}$, hal ini dimaksudkan agar pada kondisi kedalaman waktu surut masih dapat untuk menaik turunkan kapal.

- Berat kapal yang akan naik turun slipway dan ukuran utama kapal = 150 TON LWT

- $\quad$ Sarat kapal pada kondisi kosong Tk = 1,18 meter Tinggi lori transfer beserta ganjel $=0,80$ meter

Tinggi lori peluncur $=1,20$ meter

Tinggi total kapal beserta lori lorinya $=3,18$ meter

Rencana kedalaman air di ujung slipway:

- Kedalaman pada waktu air surut harus lebih besar dari tinggi total kapal dan lori-lorinya = 3,18 meter

- Kedalaman perairan pada waktu surut direncanakan $=3,50$ meter

- Kedalaman perairan pada waktu air pasang = $3,50+2,10=5,60$ meter

Dengan demikian kegiatan menaik turunkan kapal tidak tergantung dari pasang surut perairan sehingga dapat berlangsung sepanjang waktu.

Perencanaan panjang landasan dan sudut kemiringannya berdasarkan ketentuan dari buku Dock and Harbour Engineering volume 1, dari kedalaman yang direncanakan sudut kemiringan landasan luncur diambil $\operatorname{tg} \Phi=1 / 5$, sehingga panjang landasan =

$\frac{5,6}{1 / 2}=\frac{5,6}{0,5}=28,00 \mathrm{~m}$ 


\section{Perhitungan berat beban yang harus diterima oleh landasan slipway}

Karena slipway yang direncanakan adalah sistem melintang dan dapat digunakan untuk pembuatan bangunan baru dan perbaikan kapal, maka beban yang harus diterima slipway adalah sebagai berikut :

- Berat kapal (150 TON LWT)

- Berat lori transfer 20 TON

- Berat lori peluncur 40 TON

Jadi berat total yang harus didukung slipway $=210$ TON

\section{Rencana pendistribusian beban pada landasan (waktu kapal masih di darat)}

Sebelum dilakukan pendistribusian beban terlebih dahulu ditentukan beberapa faktor dibawah ini :

- $\quad$ Panjang lori direncanakan = 32,00 meter

- Jarak antara rel = 4,00 meter

- Jarak antara sumbu roda lori = 1,20 meter

- Jumlah roda lori = 32 buah

Untuk mempermudah perhitungan, maka lori peluncur dibagi 4 bagian yang sam dan masingmasing menerima beban yang sama beratnya.

Berat per bagian lori $=210 / 4=52,50$ ton

Tiap bagian lori terdiri dari 2 rel, beban yang diterima tiap rel $=52,5 / 2=26,25$ ton

Untuk satu rel terdapat 4 roda, tiap roda akan menahan beban $=26,25 / 4=6,56$ ton

Jadi beban yang harus ditahan slipway pada tiap roda $=6,56$ TON. Keadaan ini terjadi pada waktu kapal selruhnya masih berada di darat, dimana bouyancy belum bekerja.

Perhitungan beban waktu kapal menempuh jarak 12 meter dari garis air surut

$\operatorname{Tg} \Phi=1 / 5$

Sudut kemiringan $=11^{\circ} 18^{\prime} 36^{\prime}$

$\mathrm{T}=$ sarat kapal

$\mathrm{T}=(12 \mathrm{~m} \times 0,2)-2=0,4$ meter

$\gamma \mathrm{V}=$ gaya tekan keatas air laut

$\mathrm{Cb}=0,50$

$\gamma \mathrm{V}=32,00 \times 6,00 \times 0,4 \times 0,50 \times 1,025 \times 1,003=$ 39,47 TON

Berat kapal G = 150 TON LWT

Berat kapal setelah mendapat gaya tekan air $=150-$ $39,47=110,53$

Berat lori transfer $=20 \mathrm{TON}$

Berat lori peluncur $=40 \mathrm{TON}$

Berat total

$=110,53+20,00+40,00=170,53$ ton

Beban yangditerima rel tiap lori
$=170,53 / 4=42,63$ ton

Beban untuk satu rel

$=42,63 / 2=21,315$ ton

Beban yang diterima tiap roda lori

$=21,315 / 4=5,33$ ton

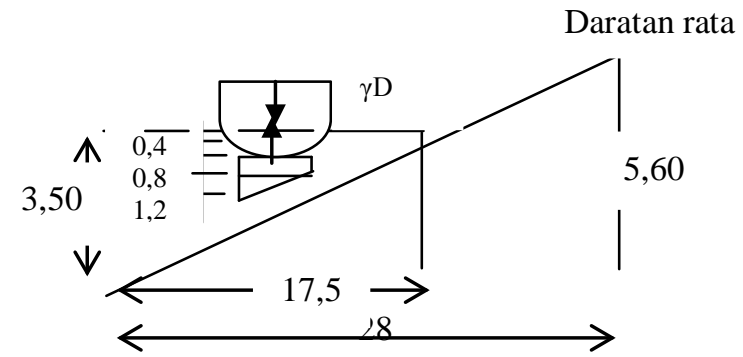

Gambar 1. Pembebanan kapal pada waktu kapal menempuh jarak 12 meter dari garis air surut

\section{Pembebanan pada saat kapal telah sampai pada akhir landasan luncur \\ Daratan rata}

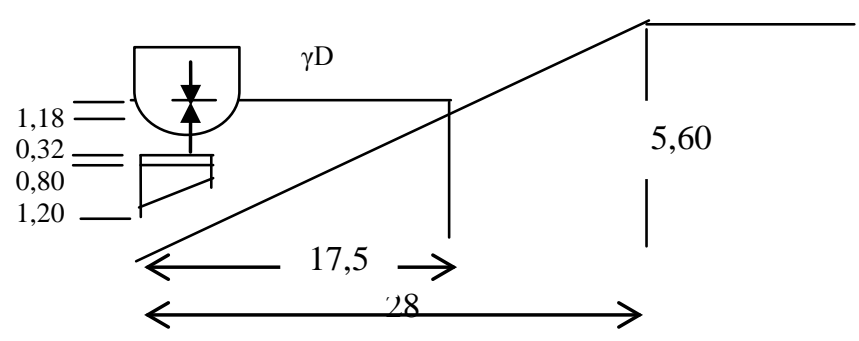

Gambar 2. Pembebanan kapal pada saat telah sampai pada akhir landasan luncur

Sarat air $\mathrm{T}=1,18$ meter

Kapal sudah mengapung bebas

$\gamma \mathrm{V}=\mathrm{G}$ maka beban diterima landasan hanya berat lori peluncur dan lori transfer saja yaitu sebesar 60 ton.

Beban yang diterima rel pada satu lori

$=210 / 4=52,50$ ton

Beban yang diterima tiap rel

$=52,5 / 2=26,25$ ton

Tiap roda menerima beban

$=26,25 / 4=6,56$ ton

Dari hasil perhitungan diatas, selanjutnya dapat diketahui beban yang bekerja sepanjang landasan slipway, dimana makin jauh dari awal landasan beban yang diterima landasan makin kecil, karena kapal sudah mendapatkan gaya tekan air keatas (buoyancy), sehingga hasil dari perhitungan pembebanan ini dapat digunakan dasar perhitungan pondasi slipway. 


\section{PERENCANAAN \\ SLIPWAY \\ Perhitungan Balok Induk} 30x40 cm

Direncanakan menggunakan balok ukuran

Beban tiap roda 6,56 ton $\rightarrow$ diambil $\mathrm{P}=7000 \mathrm{~kg}$

$=68541,67 \mathrm{~N} \approx 69 \mathrm{KN}$

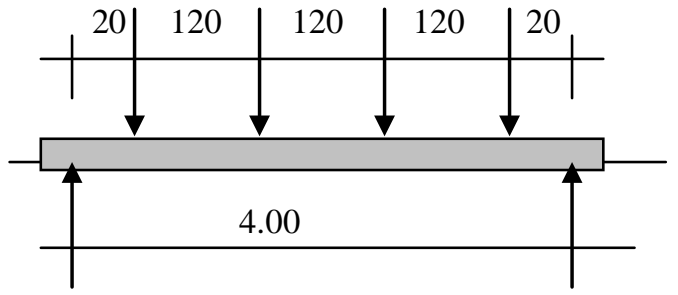

Gambar 3. skema pembebanan

- Pembebanan

Dead Load :

Balok / BS = 0,3x0,4x2400

$$
=288 \mathrm{~kg} / \mathrm{m}^{\prime}=2,82 \mathrm{KN} / \mathrm{m}^{\prime}
$$

Berat rel $=$ ditaksir

$$
\begin{aligned}
=50 \mathrm{~kg} / \mathrm{m}^{\prime} & =0,489 \mathrm{KN} / \mathrm{m}^{\prime} \\
\mathrm{E} & =3,309 \mathrm{KN} / \mathrm{m}
\end{aligned}
$$

Reaksi yang timbul :

$$
\begin{aligned}
\mathrm{RA}=\mathrm{RB}= & 1 / 2 \mathrm{q} l+1 / 2 \varepsilon \mathrm{P} \\
& =(1 / 2 \times 3,309 \times 4)+(1 / 2 \times 69 \times 4) \\
& =144,618 \mathrm{KN}
\end{aligned}
$$

Momen yang timbul :

$$
\begin{aligned}
\text { M LL } & =\text { RA. } 2-\mathrm{P}(1,8 \times 0,6) \\
& =(144,618 \times 2)-(69 \times 2,4) \\
& =123,636 \mathrm{KNM} \\
\text { M DL } & =1 / 8 \mathrm{q}^{2} \\
& =1 / 8 \times 3,309 \times 4^{2}=6,628 \mathrm{KNM} \\
\text { MR } & =1,2 \mathrm{MDL}+1,6 \mathrm{MLL} \\
& =(1,2 \times 6,628)+(1,6 \times 123,636) \\
& =205,76 \mathrm{KNM}
\end{aligned}
$$
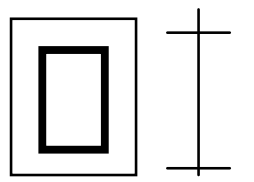

$$
\mathrm{d}=\mathrm{h}-80=400-80
$$$$
=320 \mathrm{~mm}
$$

$$
\begin{aligned}
& \mathrm{M}_{\mathrm{u}}=\varnothing \mathrm{bd^{2 }} \mathrm{k} \rightarrow \mathrm{k}=\frac{\mathrm{M}_{\mathrm{u}}}{\varnothing \mathrm{bd^{2 }}}=\frac{205,76 \times 10^{6}}{0,8 \times 300 \times 320^{2}} \\
= & 8,372
\end{aligned}
$$

dari table 29 (buku perencanaan beton bertulang ) didapat $\rightarrow \rho=0,0253$

Luas tulangan : As $=\rho b d$

$$
\begin{aligned}
& =0,0253 \times 300 \times 320 \\
& =2428,8 \mathrm{~mm}^{2}=24,288 \mathrm{~cm}^{2}
\end{aligned}
$$

Dipakai tulangan : 12 Ø $16 \mathrm{~mm}=26,1248 \mathrm{~cm}^{2}$
Atau $9 \emptyset 19 \mathrm{~mm}=25,505 \mathrm{~cm}^{2}$

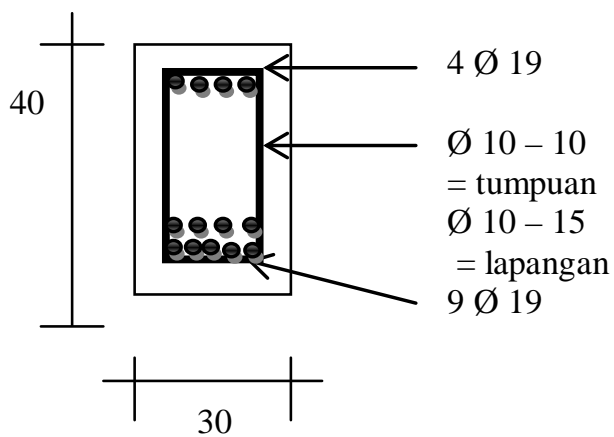

Gambar 4. Tulangan balok

- Tulangan Geser :

$\mathrm{D}_{\text {max }}=2 \mathrm{P}=2 \times 69 \mathrm{KN}=138 \mathrm{KN}=138 \times 10^{3} \mathrm{~N}$

$\mathrm{v}_{\mathrm{u}}=\frac{V u}{b . d}=\frac{138.000}{300 \times 320}=1,4375 \mathrm{Mpa}$

menurut table 15 untuk mutu beton $\mathrm{f}_{\mathrm{c}}^{\prime}=35 \mathrm{MPa}$ $\varnothing \mathrm{v}_{\mathrm{c}}=0,59 \mathrm{Mpa}$

$\mathrm{V}_{\mathrm{u}}>\varnothing \mathrm{v}_{\mathrm{c}} \rightarrow 1,4375>0,59$

$\rightarrow$ perlu tulangan geser

$\varnothing \mathrm{v}_{\mathrm{s}}=\left(\mathrm{v}_{\mathrm{u}}-\varnothing \mathrm{v}_{\mathrm{c}}\right)=1,4375-0,59$

$$
=0,8475 \mathrm{MPa}<2,37 \mathrm{MPa}
$$

$\mathrm{A}_{\mathrm{s}}$ sengkang $=\frac{\left(v_{u}-\phi \cdot v_{c}\right) \cdot b \cdot y}{\phi \cdot f_{y}}$

$$
\begin{aligned}
& =\frac{(1,4375-0,59) \cdot 300 \times 1400}{0,6 \times 400} \\
& =1483,125 \mathrm{~mm}^{2} \\
& =14,83125 \mathrm{~cm}^{2}
\end{aligned}
$$

$\mathrm{A}_{\mathrm{s}}$ sengkang minimum $=\frac{b \cdot y}{3 f_{y}}=\frac{300 \times 400}{3 \times 400}$

$$
=350 \mathrm{~mm}^{2}=3,5 \mathrm{~cm}^{2}
$$

$A_{s}$ sengkang $>A_{s}$ sengkang minimum

$$
\begin{aligned}
& \text { Tulangan geser yang diperlukan }=\frac{14,83125}{2} \\
&=7,4156 \mathrm{~cm}^{2} \\
& \text { Dipakai tulangan } \varnothing 10-100 \rightarrow\left(7,85 \mathrm{~cm}^{2}\right)
\end{aligned}
$$

\section{Perhitungan Kolom}

Direncanakan menggunakan ukuran 40 x $40 \mathrm{~cm}$

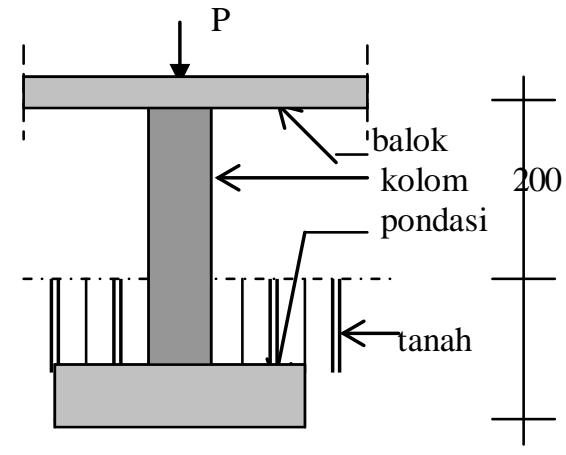


Berat sendiri kolom $=0,4 \times 0,4 \times 2400 \times 9,7917$

$$
=7520,0208 \mathrm{~N}=7,52 \mathrm{KN}
$$

Kolom dengan menggunakan sengkang

* Beban hidup $($ LL ) $=69$ x 4 x 1,6

$$
=441,60 \mathrm{KN}
$$

* Beban mati ( DL) :

- Balok = (3,309 x 4$)=13,236 \mathrm{KN}$

- Kolom $=($ 7,52 x 2$)=15,04 \mathrm{KN}$

$$
=28,276 \mathrm{KN} \times 1,2
$$$$
=33,9315 \mathrm{KN}
$$

$$
\begin{aligned}
& =441,60 \mathrm{KN}+\quad 33,9315 \mathrm{KN} \\
\mathrm{P}_{\mathrm{u}} & =475,5312 \mathrm{KN}
\end{aligned}
$$

Luas penampang kolom yang diperlukan :

$$
\begin{aligned}
\text { A }_{\mathrm{g} \text { perlu }} & =\frac{P_{u}}{0,8 \phi\left(0,85 \cdot f_{c}\right)(1-p g)+\left(f_{y} \cdot p g\right)} \\
& =\frac{0,8 \varnothing\left[\left(0,85 f_{c}{ }^{\prime}\right)(1-\rho g)+\left(f_{\mathrm{y}} \cdot \rho g\right)\right]}{0,8 . \phi(0,85 \times 40)(1-0,03)+(400 \times 0,03)} \\
& =23,838976 \times 10^{3} \mathrm{~mm}^{2}=238,38976 \mathrm{~cm}^{2}
\end{aligned}
$$

Kolom bujur sangkar $=\sqrt{238,38976}=15,4398 \mathrm{~cm}$

Sehingga kolom (40 x 40) cm dapat dipakai.

Hitungan tulangan :

$\mathrm{P}_{\mathrm{u}}=238,38976 \mathrm{KN}$

$\mathrm{M}_{\mathrm{u}}=\mathrm{M}_{\mathrm{u} 1}+\mathrm{M}_{\mathrm{u} 2}$

$=\mathrm{P}(1,4+0,2) \times 1,6+1 /\left.8 \mathrm{ql}\right|^{2}$

$=(89 \times 1,6 \times 1,6)+\left(1 / 8 \times 24,9 \times 4^{2}\right)$

$=226,545 \mathrm{KNM}$

$\mathrm{e}=\frac{M_{u}}{P_{u}}=\frac{226,545}{238,38976}$

$\rho=\rho^{\prime}=\frac{A_{s}}{b d}=2 \% / 2=0,01$

$\mathrm{d} \quad=70 \mathrm{~mm}$

As $=$ As' $=\rho b d=0,01 \times 400 \times 330$

$=1320 \mathrm{~mm}^{2}=13,2 \mathrm{~cm}^{2}$

Dipakai tulangan $6 \varnothing 19 \rightarrow\left(14,0034 \mathrm{~cm}^{2}>13,20\right.$ $\mathrm{cm}^{2}$ )

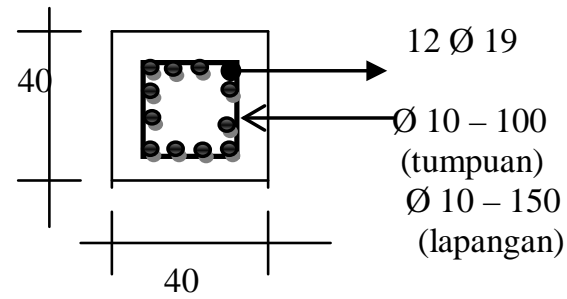

Gambar 5. Tulangan kolom

\section{Perhitungan Pondasi :}

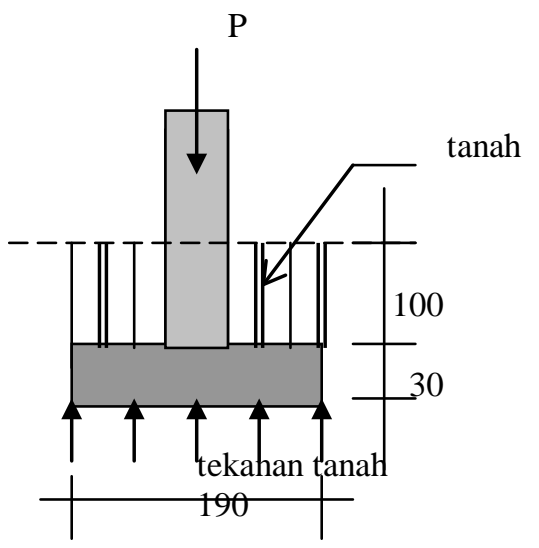

Gambar 6. skema pondasi

Berat pondasi $/ \mathrm{m}^{2}$

$=0,3 \times 2400 \times 9,7917=7,05 \mathrm{KN} / \mathrm{m}^{2}$

Berat tanah $\mathrm{h}=1 \mathrm{~m}$ '

$=1 \times 1,3 \times 9,7917=12,73 \mathrm{KN} / \mathrm{m}^{2}$

Beban luar $/ \mathrm{m}^{2}$

$=144,16 /(1,9 \times 1,9)=39,934 \mathrm{KN} / \mathrm{m}^{2}$

$\mathrm{P}=59,715 \mathrm{KN} / \mathrm{m}^{2}$

Tekanan tanah yang timbul dibawah pondasi $=1,3 \times 59,715=77,62716 \mathrm{KN} / \mathrm{m}^{2}$

Tekanan ijin tanah diambil $240 \mathrm{KPa}$

$\mathrm{f}_{\mathrm{c}}$, kolom $=35 \mathrm{MPa}$

$\mathrm{f}_{\mathrm{c}}{ }^{\prime}$ pondasi $=35 \mathrm{MPa}$

$\mathrm{f}_{\mathrm{y}} \quad=400 \mathrm{MPa}$

Tekanan ijin efektif untuk mendukung beban total $=240-77,62716=162,3724 \mathrm{KN} / \mathrm{m}^{2}$

A perlu $=\frac{446,5672}{162,3724}=2,75 \mathrm{~m}^{2}$

Pondasi direncanakan bujur sangkar ( 190 x 190 ) $=3,61 \mathrm{~m}^{2}>2,75 \mathrm{~m}^{2}$

tebal pondasi direncanakan $=30 \mathrm{~cm}=300 \mathrm{~mm}$ tinggi efektip $=300-50-25=225 \mathrm{~mm}$ 


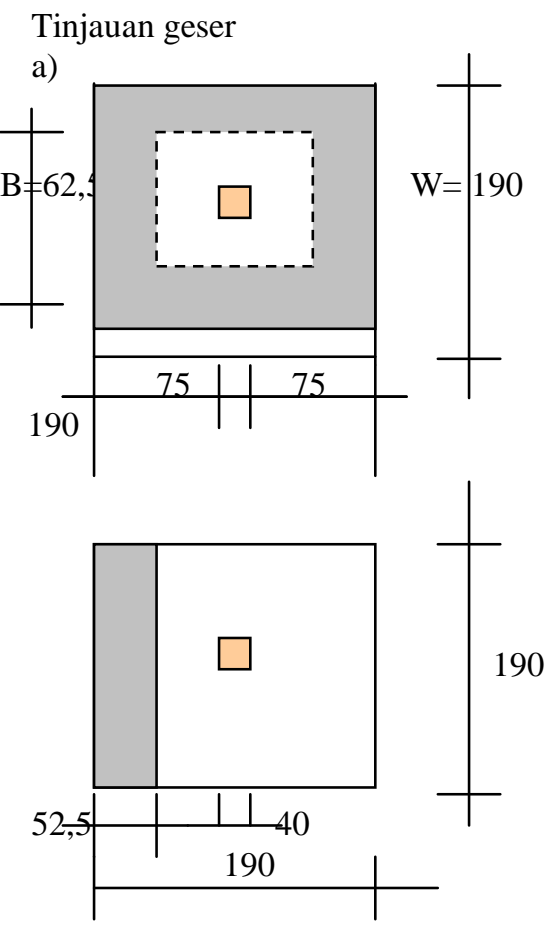

a) untuk arah kerja 2 arah

$$
\begin{aligned}
\mathrm{B} & =\text { lebar kolom }+2(1 / 2 \mathrm{~d}) \\
& =400+225=625 \mathrm{~mm}
\end{aligned}
$$

Gaya geser total terfaktor pada penampang kritis

$$
\begin{aligned}
\mathrm{V}_{\mathrm{u}} & =\mathrm{p}_{\mathrm{u}}\left(\mathrm{W}^{2}-\mathrm{B}^{2}\right) \\
& =162,3724\left(1,9^{2}-0,625^{2}\right) \\
& =552,7376 \mathrm{KN}
\end{aligned}
$$

Pondasi bujur sangkar $\rightarrow \beta_{\mathrm{c}}=1$

$\mathrm{V}_{\mathrm{c}}=\left(1+2 / \beta_{\mathrm{c}}\right)+\left(2 \sqrt{ } \mathrm{f}_{\mathrm{c}}{ }^{\prime}\right) \cdot \mathrm{b} \cdot \mathrm{d}$

$$
=\left(6 \sqrt{ } f_{c}{ }^{\prime}\right) b_{0} \cdot d
$$

$V_{c} \max =\left(4 \sqrt{ } f_{c}^{\prime}\right) b_{o} \cdot d$

$$
\begin{aligned}
& =(4 \sqrt{3} 35)(625 \times 4) \\
& =13.311 .179,51 \mathrm{~N} \\
& =13.311,18 \mathrm{KN} \\
\varnothing \mathrm{V}_{\mathrm{n}}= & \varnothing \mathrm{V}_{\mathrm{c}}=0,6 \times 13.311,18 \\
& =7.986,70 \mathrm{KN} \\
\rightarrow \mathrm{V}_{\mathrm{u}}< & \varnothing \mathrm{V}_{\mathrm{c}}=552,7376<7.986,70 \mathrm{KN}
\end{aligned}
$$

b). untuk arah kerja satu arah

gaya geser total terfaktor yang bekerja pada penampang kritis :

$$
\begin{aligned}
\mathrm{V}_{\mathrm{u}} & =\mathrm{p}_{\mathrm{u}} \cdot \mathrm{W} \cdot \mathrm{G} \\
& =(162,3724)(1,9)(0,525) \\
& =161,967 \mathrm{KN}
\end{aligned}
$$

kuat geser beton

$$
\begin{aligned}
\mathrm{V}_{\mathrm{c}} & =1 / 6\left(\sqrt{\mathrm{f}_{\mathrm{c}}}\right) \mathrm{b}_{\mathrm{w}} \cdot \mathrm{d} \\
& =1 / 6(\sqrt{35})(1899)(225) \\
& =421,521 \mathrm{KN} \\
\varnothing \mathrm{V}_{\mathrm{n}} & =\varnothing \mathrm{V}_{\mathrm{c}}=0,6 \times 421,521 \\
& =252,912 \mathrm{KN}
\end{aligned}
$$$$
\rightarrow \mathrm{V}_{\mathrm{u}}<\varnothing \mathrm{V}_{\mathrm{c}}=161,967<252,912 \mathrm{KN}
$$
sehingga pondasi memenuhi syarat geser

Penulangan :

$$
\begin{aligned}
\mathrm{M}_{\mathrm{u}} & =\mathrm{p}_{\mathrm{u}} \mathrm{F}(1 / 2 \mathrm{~F}) \mathrm{W} \\
& =162,3724(0,75)(1 / 2 \times 0,75)(1,9) \\
& =86,767 \mathrm{KNM} \\
\mathrm{k} \text { perlu } & =\mathrm{M}_{\mathrm{u}} / \varnothing \mathrm{b} \mathrm{d}^{2} \\
& =86,767 /(0,8)(1900)\left(225^{2}\right)=1,1275
\end{aligned}
$$

dari table A-15 (buku truktur beton bertulang) $\rho$ perlu $<\rho$ min $=0,0047 \rightarrow \mathrm{k}$ min $=1,3514$ $\mathrm{A}_{\mathrm{s}}$ perlu $=\rho \mathrm{bd}=(0,0047)(1900)(225)$

$$
=2009,25 \mathrm{~mm}^{2}=20,0925 \mathrm{~cm}^{2}
$$

dipakai tulangan : 10 D.16

$$
=20,0096 \mathrm{~cm}^{2}>20,0925 \mathrm{~cm}^{2}
$$

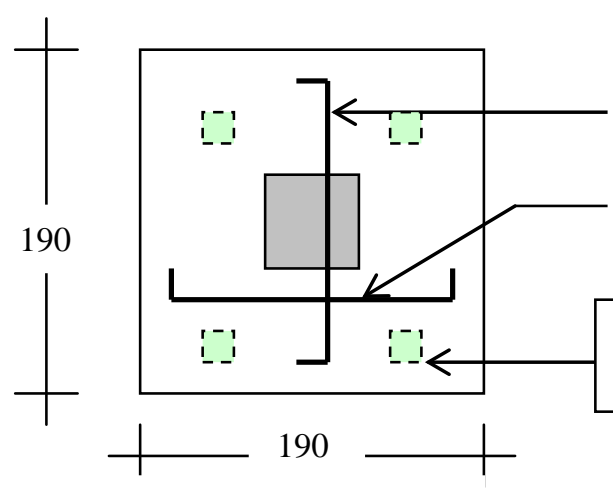

Gambar 7. pondasi + tulangan

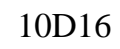

10D16

Strauspal Ø30 /mini pileø30 


\section{KESIMPULAN}

Penentuan pembebanan slipway 150 ton, didapatkan dari LWT kapal, lori transfer dan lori peluncur. Beban yang ditahan oleh sebuah roda = 6,56 ton.

Dari beban tersebut berdasarkan dimensi kapal direncanakan slipway yang berupa bidang tercelup air dan bagian yang diatas air, dan dihasilkan dimensi slipway 28 x 28 meter.

\section{DAFTAR PUSTAKA}

1. Harrington, 1992, Marine Engineering, Sname

2. H.E. Rossels, Principle Of Naval Architecture, Sname.

3. J.E. Engstrom and I.O. Engvall, Method For Selection Of An Optimum Fishing Vessel For Infestment Purpose, FAO, Rome Italy.

4. John Fyson, Design Of Small Fishing Vessel, FAO, Rome Italy.

5. Robert Toggart, Ship Design and Construction

6. Suyono Sosrodarsono, Ir. Kazuto Nakazawa,1980. PT Pradnya Paramita, Jakarta.

7.W.C.Vis, Ir , Gideon Kusuma, Ir. M.Eng, 1993, Dasar-dasar Perencanaan Beton Bertulang, Erlangga Jakarta.

8. W.C.Vis, Ir , Gideon Kusuma, Ir. M.Eng, 1993 Grafik dan Tabel Perhitungan Beton Bertulang, Erlangga Jakarta. 